\title{
Genetic homogeneity among geographically distant populations of the blister worm Polydora websteri
}

\author{
Lauren N. Rice, Sara Lindsay, Paul Rawson* \\ School of Marine Sciences, University of Maine, Orono, Maine 04469, USA
}

ABSTRACT: The shell-boring polychaete worm Polydora websteri, also known as blister worm, is a pest species that infests the shells of several commercially important shellfish species, including those of the oysters Crassostrea virginica and $C$. gigas. Historical records indicate that infestations of blister worm have impacted shellfish culture worldwide for over $100 \mathrm{yr}$. Although a lot of attention has been given to the burrowing habits of and damage created by blister worms, few studies have examined the levels of population genetic structure in this cosmopolitan species. We examined the patterns of sequence divergence at the mitochondrial cytochrome $c$ oxidase subunit I (mtCOI) gene for individual $P$. websteri specimens sampled from oysters and scallops collected from shellfish farms along the US Atlantic and Gulf coasts, and Hawaii. The mtCOI sequences we obtained were aligned and compared with published sequences for $P$. websteri adults and larvae sampled at an oyster farm in Guangdong Province, China. We observed little genetic variation, overall, and no differentiation between populations of $P$. websteri, a pattern that suggests high levels of connectivity among locations. It is unlikely that natural dispersal alone can account for this lack of differentiation; rather, our results are consistent with the hypothesis that human-mediated introductions have led to genetic homogeneity across large geographic distances for this pest polychaete species.

KEY WORDS: Spionid polychaete $\cdot$ Divergence · Connectivity $\cdot$ Mitochondrial COI $\cdot$ Pest species

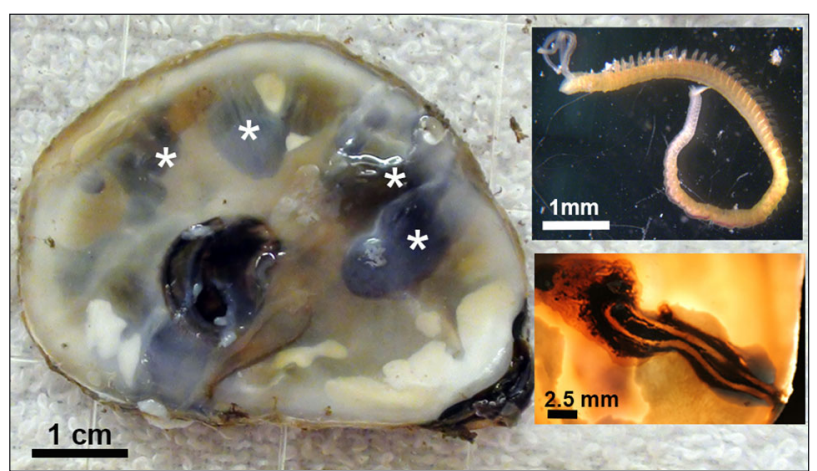

Blister worms Polydora websteri (upper right) create a distinctive U-shaped tube within the shell of their bivalve host lined with mud and debris (lower right and asterisks in image on left). In heavy infestations, several hundred worms may colonize a single shellfish host, decreasing host condition, weakening host shell, increasing host mortality rates, and negatively impacting the appearance of commercial shellfish, such as oysters, served on the half shell.

Photos: Paul Rawson \& Sara Lindsay, University of Maine

\section{INTRODUCTION}

Several spionid polychaete species in the genera Polydora, Dipolydora and Boccardia are known to bore into and form burrows within calcareous substrates, including the shells of commercially important shellfish (e.g. Blake \& Evans 1973, Simon \& SatoOkoshi 2015). One species, Polydora websteri, is considered particularly troublesome due to the severity of infestations involving this worm and the diversity of host species it infests, including rock oysters, pearl

(C) The authors 2018. Open Access under Creative Commons by Attribution Licence. Use, distribution and reproduction are unrestricted. Authors and original publication must be credited. 
oysters, scallops and mussels. Adult P. websteri, also known as blister worms, typically grow to around 100 segments and $20 \mathrm{~mm}$ long (Loosanoff \& Engle 1943, Blake 1971, Nell 2007). Females of this gonochoristic species attach egg cases to the inner wall of a sediment tube lining a burrow they excavate within the host shell material (Blake 1969). Blister worm larvae may exit the egg case and maternal burrow at the 3chaetiger stage ( $~ 0.35$ to $0.4 \mathrm{~mm}$ in length) and spend several weeks developing in the plankton, metamorphosing at the 17-chaetiger stage, after which they settle on calcareous material (Hopkins, 1958, Blake 1969).

Blister worms often settle on host shells when they have reached a late-larval or early juvenile stage (Loosanoff \& Engle 1943, Hopkins 1958, Blake 1969, Haigler 1969). In some cases, worms settle in crevices near where the 2 valves of the host's shell meet. The worm subsequently builds a mud tube between the mantle and the edge or lip of the shell. In oysters, $P$. websteri larvae also settle between layers on the outside of the shell and excavate a burrow through the shell layers (Hopkins 1958, Zottoli \& Carriker 1974, Read 2010). In both cases, the worm typically creates a distinctive U-shaped tube that is lined with mud and other debris with both ends exposed to the outer shell surface (Haigler 1969, Blake \& Evans 1973, Zottoli \& Carriker 1974, Bergman et. al. 1982, Wargo \& Ford 1993). When the burrow extends through the shell to the inner nacreous layer, the shellfish host covers the intruding worm tube with a layer of nacre, resulting in the formation of a mud blister. While the impacted oyster is still fit for human consumption, the blisters filled with sediment and detrital material affect the appearance of the host shellfish, which is a particularly acute problem for oysters headed for the half-shell market (Bower 2004, Dunphy et. al. 2005). Heavy worm infestations have been associated with decreased host condition, weakened host shell and increased host mortality rates (Lunz 1940, Hopkins 1958, Zottoli \& Carriker 1974, Lafferty \& Kuris 1996, Read 2010, Sato-Okoshi et al. 2017). Given these host-pest interactions, Simon \& Sato-Okoshi (2015) and others have labeled $P$. websteri as one of the most virulent of polychaete pests to shellfish aquaculture.

Early descriptions of boring polychaetes and their burrows date back to the early to mid-1700s (see Blake \& Evans 1973), although the taxonomy of several species has been poorly resolved. For example, $P$. websteri was initially named $P$. ceaca by Webster in 1879. Webster's description, however, was incomplete and in many reports from the early 1900s this species was often confused with the closely related European species $P$. ciliata, a species that is not known to burrow into calcareous substrates (Loosanoff \& Engle 1943). Working with specimens from Milford Harbor, Connecticut, USA, Hartman developed a detailed morphological description of a North American shell-boring spionid polychaete that was formally recognized as $P$. websteri (Loosanoff \& Engle 1943). Although the species description for $P$. websteri is from a site on the East Coast of North America, recent morphological and molecular genetic work has shown that this species has a broad distribution; from Australia to China and Japan in the Pacific, to Brazil, South Africa, Venezuela, to both sides of the North Atlantic and the Black Sea in Ukraine (Simon \& Sato-Okoshi 2015).

Despite the prolonged attention from biologists and oyster farmers, little is known about the genetic connectivity among populations of this cosmopolitan species. The degree of genetic differentiation among populations of benthic marine invertebrates is often inversely related to the duration of the planktonic larval phase (e.g. Hellberg et al. 2002, Selkoe \& Toonen 2011). Although there are reports that $P$. websteri is poecilogonous and that planktotrophic and adelphophagic larvae can occur in the same brood (Haigler 1969, Simon 2015), the majority of larvae leave the burrow at an early stage (3 segments) and have a protracted period of planktonic development that should act to reduce the degree of genetic differentiation among blister worm populations, at least on a regional scale (i.e. along coastlines). At the same time, expansion of shellfish aquaculture and the broad-scale movement of host species are likely to have facilitated the spread of pest species, including many polychaete pests (e.g. Bailey-Brock 2000, Radashevsky \& Olivares 2005, Simon \& Sato-Okoshi 2015, Sato-Okoshi et al. 2017). Such inadvertent dispersal may lead to genetic homogeneity over even broader geographic scales. In this study, we assessed the degree of intra- and inter-population genetic variation in $P$. websteri using sequences for a portion of the mitochondrial cytochrome $c$ oxidase subunit I (mtCOI) gene for worms sampled from oysters obtained from 4 locations on the Atlantic and Gulf Coasts of North America, as well as Hawaii in the Pacific. We compared these sequences with several additional sequences for Asian samples of $P$. websteri, available on GenBank, to assess the levels of differentiation. among worms from different ocean basins.

\section{MATERIALS AND METHODS}

Eastern oysters Crassostrea virginica containing live Polydora websteri were obtained from the Baga- 


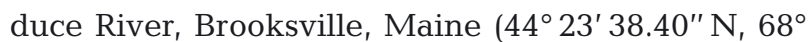
42' 14.40"W), Megansett Harbor, North Falmouth, Massachusetts $\left(41^{\circ} 39^{\prime} 21.60^{\prime \prime} \mathrm{N}, 70^{\circ} 37^{\prime} 30.00^{\prime \prime} \mathrm{W}\right)$, Fishing Creek, Hoopers Island, Maryland (38 18' 36.00" N, $\left.76^{\circ} 13^{\prime} 12.00^{\prime \prime} \mathrm{W}\right)$ and Portersville Bay, Coden, Alabama $\left(30^{\circ} 22^{\prime} 33.60^{\prime \prime} \mathrm{N}, 88^{\circ} 13^{\prime} 31.20^{\prime \prime} \mathrm{W}\right)$ (Fig. 1A). In addition, Pacific oysters C. gigas with live $P$. websteri were obtained from Kualoa Ranch,

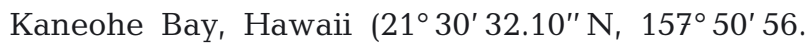
$\left.60^{\prime \prime} \mathrm{W}\right)$ (Fig. 1B). On arrival at either the Darling Marine Center (Walpole, Maine, USA) or the University of Maine (Orono, Maine), the oysters were placed in recirculating tanks containing seawater maintained at $\sim 16-18^{\circ} \mathrm{C}$ and 30 ppt salinity until they were processed. Two methods were used to obtain intact blister worms. In the first method, the oysters were sacrificed, shucked, and the valves separated. Pliers were used to crack individual valves to expose worm burrows. Pieces of shell containing burrows were immersed in finger bowls containing seawater with $3.5 \% \mathrm{MgCl}_{2}$ to relax and facilitate the extraction of full-length worms. Shell pieces were examined under a dissecting scope at $\times 10-30$ magnification, and worms were gently removed whole, using dental tools. In the second method, intact oyster valves were soaked in $200 \mathrm{ml}$ of seawater containing $200 \mu \mathrm{l}$ of peppermint essential oil. After soaking the valves for 2-4 h, worms were collected using transfer pipets as they emerged from their burrows and were transferred to fresh seawater.

Preliminary observations of pigmentation patterns and other morphological features were used to separate $P$. websteri from closely related species, especially any $P$. cornuta living on the exterior of the shellfish valves (see 'Results'). Those identified as $P$. websteri were placed in 70\% ethanol:30\% seawater for preservation and eventual DNA isolation. We also preserved a subset of worms from the Bagaduce River, Maine, and Kaneohe Bay, Hawaii for combined DNA and more detailed morphological analyses. For these, we separated each worm into thirds and preserved the anterior and posterior thirds in seawater with $10 \%$ buffered formalin. After $48 \mathrm{~h}$ the fixed segments were transferred into a solution of $70 \%$ ethanol:5\% glycerin in distilled water and subsequently used for detailed morphological analysis based on the characteristics of P. websteri outlined in Read (2010), Sato-Okoshi \& Abe (2013) and Sato-Okoshi et al. (2013). The middle third of each of these specimens were preserved in $95 \%$ ethanol for DNA analysis.

DNA was isolated from ethanol-preserved $P$. websteri using a Wizard Genomic DNA Purification kit (Promega), following the manufacturer's protocol.

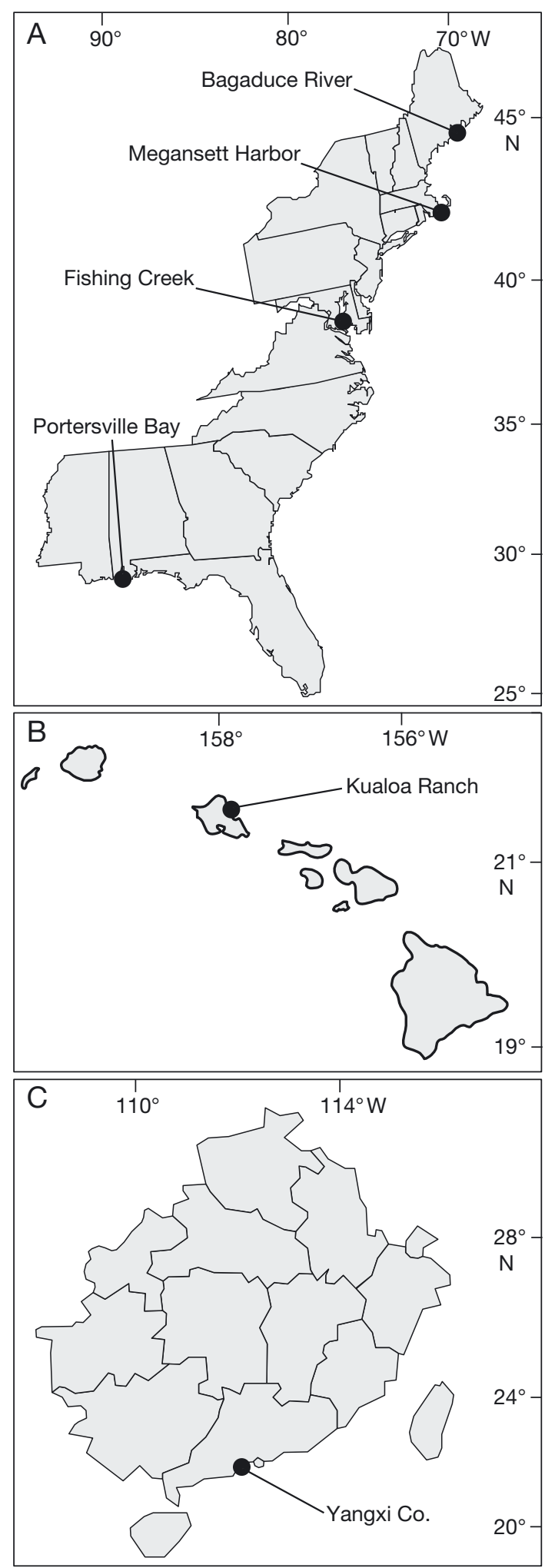

Fig. 1. Locations along (A) the Atlantic and Gulf of Mexico coasts of the USA and (B) on Hawaii, where Polydora websteri was sampled in this study. (C) Location in Yangxi County, Guangdong Province, China, where Ye et al. (2017) obtained their samples of $P$. websteri 
Isolated DNA was used in PCR targeting an 843 base pair (bp) portion of the mitochondrial cytochrome oxidase I (mtCOI) gene. $\mathrm{PCR}$ reactions were run in a $25.0 \mu \mathrm{l}$ reaction mixture containing $1.0 \mu \mathrm{l}$ of DNA template, $0.5 \mu \mathrm{l}$ of $10 \mathrm{mM}$ deoxynucleotide triphosphates (dNTPs), $0.75 \mu \mathrm{l}$ of $50 \mathrm{mM} \mathrm{MgCl}_{2}, 2.5 \mu \mathrm{l}$ of $10 \times$ PCR buffer, $0.25 \mu$ l of $30 \mu \mathrm{M}$ forward (PwCO1LP-For; 5'-GGC AAA GGC AAA AAT AGC CCC-3') and reverse (PwCO1LP-Rev; 5'-GCT ATA CTT CTA AGA GGA ATG TGA GTA G-3') primers and $1 \mathrm{U}$ of Taq DNA polymerase (Life Technologies). The primers were designed by aligning the mtCOI sequences for $P$. websteri available on GenBank (accession numbers KP231331 and KR337461 to KR337472; published by Ye et al. 2017). The reaction conditions included an initial denaturation at $94^{\circ} \mathrm{C}$ for $2 \mathrm{~min}$ followed by 29 cycles of $94^{\circ} \mathrm{C}$ denaturation for $20 \mathrm{~s}, 50^{\circ} \mathrm{C}$ primer annealing for $30 \mathrm{~s}$, and a $72^{\circ} \mathrm{C}$ extension $2 \mathrm{~min}$ and $1 \mathrm{cycle}$ of $72^{\circ} \mathrm{C}$ for $10 \mathrm{~min}$ for final extension. Successful PCR amplification was confirmed by gel electrophoresis using a $1.5 \%$ agarose gel with ethidium bromide staining. PCR products were separated from excess primers using a Purelink PCR Cleanup Kit (Life Technologies).

Purified PCR products from individual worms were direct sequenced in both directions using the original PCR primers. All sequencing reactions were run at the University of Maine DNA Sequencing Facility using an ABI model 3730 DNA Sequencer with XL upgrade. The resulting chromatograms were manually edited using the software CHROMAS (www. technelysium.com.au/wp/chromas/). We obtained sequences for a minimum of $1 P$. websteri from Massachusetts to a maximum of $16 P$. websteri from Alabama. The $54 \mathrm{mtCOI}$ sequences we obtained from US $P$. websteri were aligned with $13 \mathrm{mtCOI}$ sequences available on Genbank for $P$. websteri that were obtained from $C$. hongkongensis oysters sampled from Yangxi County, Guangdong Province, China (Ye et al. 2017; Fig. 1C) using the program CLUSTAL Omega (www.ebi.ac.uk/Tools/msa/ clustalo/). Sequences were trimmed to a common length of $794 \mathrm{bp}$ and the program DNAsp (ver 5.10.1; Librado \& Rozas 2009) was used to estimate haplotype and nucleotide diversity among the trimmed sequences from each location (except Massachusetts). A phylogeny for the 22 unique $P$. websteri mtCOI haplotypes (794 bp), with a $P$. haswelli mtCOI sequence serving as an outgroup, was estimated using a maximum likelihood approach as implemented in the program PhyML (Guindon et al. 2010). The best-fit model of nucleotide substitution used to construct the phylogeny was estimated using the
Smart Model Selection (Lefort et al. 2017) module within PhyML. The best-fit substitution model (Akaike's information criterion, AIC $=3557.25$ ) was a general time reversible (GTR) with the proportion of invariable sites $(I=0.379)$. The initial tree for the heuristic search was obtained using the BioNJ algorithm and the tree topology search employed the nearest-neighbor interchange approach. A bootstrap approach $(n=1000)$ was employed to determine statistically significant clade structure within the phylogeny. The resulting phylogeny was visualized using the program TREEVIEW in the ETE Toolkit (HuertaCepas et al. 2016). In addition, we used the program TCS (Clement et al. 2000) to estimate a haplotype network via statistical parsimony with a $95 \%$ probability of parsimony cut-off. The program Population Analysis with Reticulate Trees (POPART ver 1.7; Leigh \& Bryant 2015) was used to draw the network and incorporate site-specific haplotype frequencies.

\section{RESULTS}

The oysters we received from the shellfish farms in Hawaii, Alabama, Maryland and Maine (10-50 per site), as well as a single oyster from Massachusetts, all contained shell-boring spionid worms. When the oysters were held in recirculating tanks prior to processing, the palps of live worms could easily be discerned extending from both valves of individual oysters. Once the oyster valves were separated, Ushaped tubes and mud blisters like those described for Polydora websteri by Blake \& Evans (1973) and Zottoli \& Carriker (1974) were clearly visible.

The adult worms that we isolated in this study were up to $20 \mathrm{~mm}$ and approximately 100 segments long. All had a modified fifth segment up to 2 times longer than neighboring segments. Fifth-segment chaetae included falcate spines with a lateral flange arranged in a shallow U-shape, hastate companion chaetae interspersed with the spines, and fascicles of notochaetae and neurochaetae above and below the spines, respectively. Branchiae were present from segment 7 almost to the posterior end; the posterior, in turn, terminated in a flared, disc-shaped pygidium noticeably larger than the posterior-most segments. The pygidium was lighter colored, appearing white to bright yellow relative to the rest of the body. The prostomium was typically weakly notched and bilobed. A caruncle was present in all specimens and extended back to the third and, in some cases, fourth segment depending on worm size. We did not observe an occipital cirrus (also known as nuchal cirrus 
or nuchal tentacle, Light 1978) in any of the specimens we sampled. Body coloration varied from pale to light tan often taking on an orange-red appearance due to gut and surface blood vessel coloration or yellow appearance in ripe individuals. Black pigmentation was restricted to the palps. In some individuals, black pigment ran the length of the outer edge of the ciliated food groove on the palps, while in others, black pigmentation was weak or patchily distributed along the food groove and superficially resembled pigment bars when the palps were coiled (see Fig. 1a in Ye et al. 2017). These morphological features are consistent with the descriptions of $P$. websteri provided in Read (2010), Sato-Okoshi \& Abe (2013) and Ye et al. (2017).

The oysters from Maine, Maryland, and Hawaii were heavily infested with $P$. websteri; in some cases, we estimated over 100 worms per oyster with many worm burrows layered on top of one another to form galleries. Infestations in the oysters from Massachusetts and Alabama were less severe, with fewer than 10 worms per oysters. We sampled DNA from 11-16 worms per site from multiple oysters except for the Massachusetts site from which we only obtained 1 intact adult $P$. websteri (Table 1). We obtained DNA from 4 specimens from Maine and 2 from Hawaii, for which we also conducted more detailed morphological analyses (see summary of characteristics above). For these 6 specimens, we also sequenced a $1170 \mathrm{bp}$ portion of the nuclear 18S rRNA gene; in all 6 cases, the $18 \mathrm{~S}$ rRNA sequence was identical to the $P$. websteri sequence reported by Sato-Okoshi \& Abe (2013) (accession number AB705402, data not shown).
We combined the 54 sequences we generated for $P$. websteri sampled from the 5 US populations with the 13 unique sequences from Ye et al. (2017) available on GenBank. Haplotype diversity ranged from a low of 0.143 among worms sampled from Hawaii to 0.858 for those from Alabama, reflecting the higher number of identical sequences at the former site and a higher number of unique haplotypes at the latter site. The reduced diversity among the Hawaiian sequences was also seen in the estimates of nucleotide diversity, which were an order of magnitude lower than those observed among the sequences from all other sites. The single sequence from Massachusetts was excluded from the diversity analyses.

Out of the 54 sequences we generated, 13 represented new haplotypes not found among those reported by Ye et al. (2017). These haplotype sequences have been deposited on GenBank (accession numbers MG977702 to MG977714). The maximum likelihood phylogeny estimated from the 22 unique $P$. websteri mtCOI haplotypes in our dataset shows that sequence variation within $P$. websteri is greatly reduced relative to that between $P$. websteri and the outgroup, $P$. haswelli (Fig. 2). Although the haplotypes from Maine and Hawaiian P. websteri were restricted to a single cluster of haplotypes, the sequences from China and Alabama were distributed throughout the tree. Further, the branch lengths connecting individual haplotypes to the phylogeny were all short, there was only weak statistical support for any node within the tree (maximum bootstrap value $68 \%$ for node leading to clade with haplotypes $\mathrm{H} 7$ and H5) and there was no evidence of site-specific clade structure among $P$. websteri haplotypes. The lack of clade structure is also evident in the estimates of genetic distance (Table 2) where net genetic distances between populations are typically an order of magnitude lower than within population estimates of pair-wise genetic distance.

The lack of population structure was further illustrated in the statistical parsimony-based TCS network (Fig. 3). We observed 2 clusters of haplotypes, one connected to the network through haplotype H3 and the other through haplotype E. Haplotype H3 was identified in this analysis as the most probable outgroup haplotype, al- 


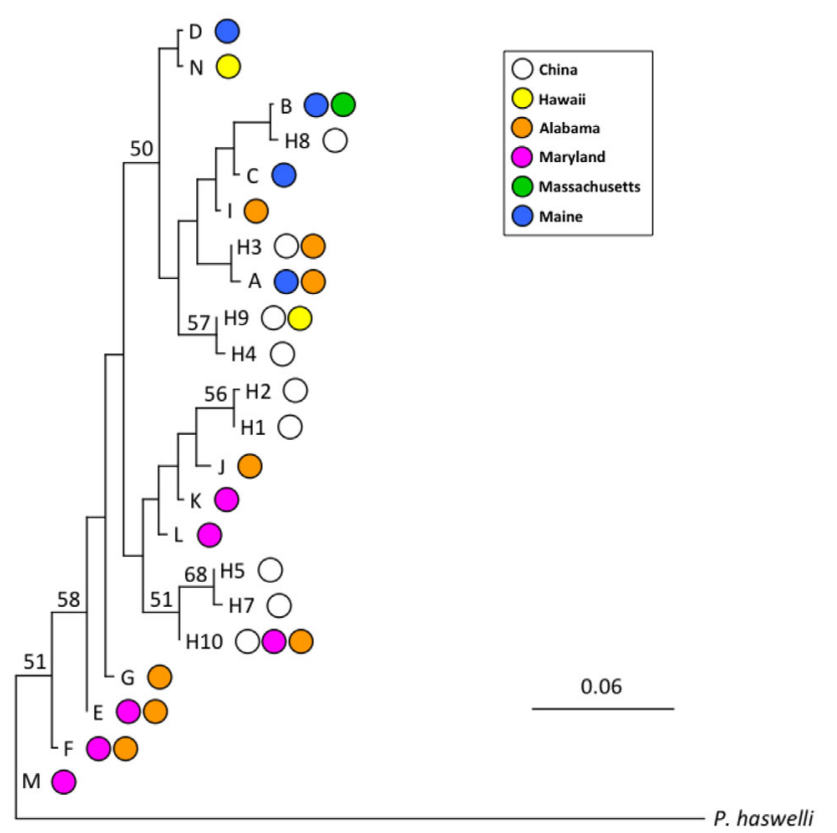

Fig. 2. A maximum likelihood phylogeny was inferred from 22 individual Polydora websteri mtCOI haplotypes with a haplotype from $P$. haswelli serving as the outgroup. The scale bar represents the number of substitutions per site while the filled circles to the right of each haplotype indicate the sampling sites where each haplotype was observed. Bootstrap values $>50 \%$ (based on 1000 bootstrap replicates) are shown next to their respective nodes

though $\mathrm{H} 3$ and $\mathrm{E}$ were only separated from one another by 1 mutational step and all other haplotypes were a maximum of 3 mutational steps from either $\mathrm{H} 3$ or E. As in the maximum-likelihood phylogeny, it is evident that haplotypes from Asia and Alabama are distributed throughout the network and that the maximum number of mutational steps separating any 2 haplotypes is 6 ; this occurs between sequences $\mathrm{H} 7$ and $\mathrm{H} 4$ or $\mathrm{H} 7$ and H8, which are all from Asia. These observations further illustrate that sequence diver-

Table 2. Pair-wise genetic distance (\% distance) estimates among the $P$. websteri mtCOI sequences within each population are shown along the diagonal (italics) while betweenpopulation total and net distance are given below and above the diagonal, respectively. Genetic distances were calculated using the Jukes-Cantor model in Mega (ver6; Tamura et al. 2013). The single sequence from Massachusetts was not included in this analysis

\begin{tabular}{|lccccc|}
\hline Site & China & Hawaii & Alabama & Maryland & Maine \\
\hline China & 0.280 & 0.025 & 0.029 & 0.063 & 0.122 \\
Hawaii & 0.290 & 0.253 & 0.051 & 0.013 & 0.086 \\
Alabama & 0.316 & 0.324 & 0.294 & 0.032 & 0.063 \\
Maryland & 0.302 & 0.357 & 0.278 & 0.198 & 0.218 \\
Maine & 0.375 & 0.327 & 0.325 & 0.431 & 0.228 \\
\hline
\end{tabular}

gence is highest among the Asian haplotypes and that overall sequence diversity within and between populations of $P$. websteri is extremely limited.

\section{DISCUSSION}

The burrowing habits and destructive potential of blister worms, including several species in the genus Polydora, have long held the attention of natural historians and shellfish culturists. More recently, an increasing number of studies have focused on molecular and population genetic variation in shell-boring polychaetes. These studies have helped elucidate and clarify features of the taxonomy of the group and have provided estimates of genetic connectivity among populations of these pest species. For example, Sato-Okoshi et al. (2017) examined the extent of genetic differentiation among 2 species of Polydora, $P$. hoplura and $P$. uncinata, sampled from Australia, Japan, and the west coast of South Africa. Given no base substitutions at 2 nuclear genes (18S and 28S rRNA) and little variation at 2 mitochondrial genes (16S and Cytb), they concluded that $P$. uncinata and $P$. hoplura should be synonymized. Just as importantly, they found no evidence of location-specific clades, even for $P$. hoplura sampled from geographically distant populations.

Our results indicate that there is a similarly striking lack of genetic differentiation among populations of $P$. websteri, even for populations from separate ocean basins. In our analyses, we included previously published sequence data for adult and larval $P$. websteri from Ye et al. (2017), who sampled from a single oyster farm in Guangdong Province, China. Among the 25 sequences Ye et al. (2017) reported, the average pair-wise genetic distance was only $0.33 \%$ and there were no more than 5 mutational steps separating any 2 haplotypes. We expanded on the Ye et al. (2017) dataset by sampling $P$. websteri from an additional 5 locations, 1 site in the Pacific and 4 sites from the Gulf and Atlantic coasts of the USA. We designed new mtCOI primers to avoid the use of redundant bases and to improve the quality of PCR amplification with $P$. websteri DNA. Our resulting sequence comparisons cover only $794 \mathrm{bp}$ of the $853 \mathrm{bp}$ of mtCOI reported by Ye et al. (2017). Even so, we found clear phylogenetic evidence (Fig. 2) that all 22 P. websteri mtCOI haplotypes are highly differentiated from a mtCOI sequence for the closest related species, P. haswelli. Among the P. websteri haplotypes, there was no evidence of clade structure and the branch lengths joining each haplotype to the tree 


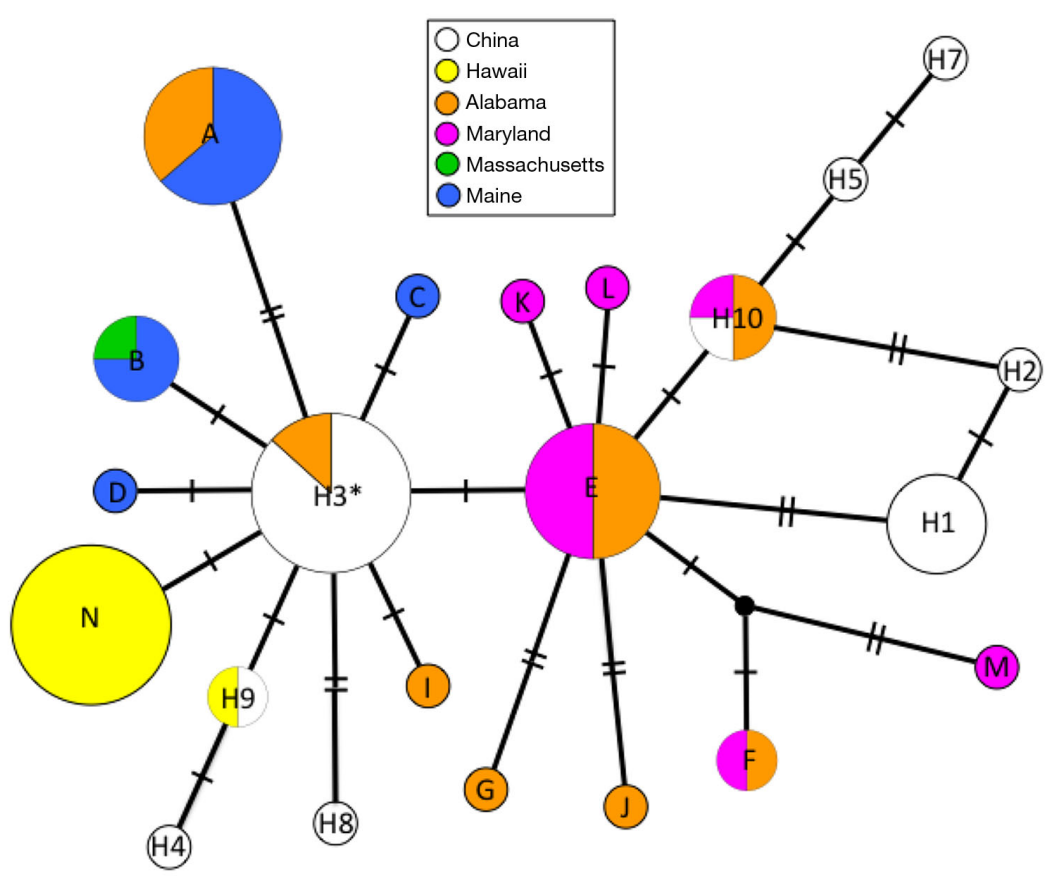

Fig. 3. We constructed a $95 \%$ maximum parsimony network for all 22 Polydora websteri mtCOI haplotypes included in this study. In this network, haplotypes are represented as circles with the size of each circle indicating the abundance of each haplotype in our dataset and the fill of each circle indicating the sampling sites where that haplotype was observed. In addition, lines along each connection between haplotypes indicate the number of mutations separating haplotype pairs. This analysis also indicated that haplotype H3 (asterisk) was the most probable outgroup haplotype

were short (typically $<0.001$ changes per site), similar to what Sato-Okoshi et al. (2017) observed among mtCOI haplotypes from P. hoplura. Further, despite the addition of 13 new haplotypes, the maximum parsimony network we estimated did not change dramatically from one presented by Ye et al. (2017). All of the new haplotypes are clustered around haplotype $\mathrm{H} 3$ or E through connections that were typically 1 or 2 steps long. Similar to what Ye et al. (2017) reported, no 2 haplotypes in the network are separated by more than 6 base changes.

Williams et al. (2017) have also published molecular genetic data for $P$. websteri. Among the 3 specimens of $P$. websteri included in their study, they observed no polymorphic sites at either mtCOI or mtCytb genes (622 bp and $367 \mathrm{bp}$ of sequence, respectively) and detected only 1 polymorphic site out of $1722 \mathrm{bp}$ at the nuclear 18S rRNA gene. The single mtCOI haplotype they identified among South African P. websteri (GenBank accession number KY677867) is identical to Chinese haplotype H3 from Ye et al. (2017). Thus, while the mean pair-wise genetic distance for all $P$. websteri sequences $(d=$ $0.32 \%$; Table 2) is similar to intraspecific mtCOI distances observed for a variety of other polychaete taxa (Carr et al. 2011), divergence between $P$. websteri populations is negligible relative to the sequence variation within populations.

The life history characteristics of a species can influence population-level patterns of genetic divergence (Hellberg et al. 2002). P. websteri females deposit egg cases, each with upwards of 50 eggs, along the wall of the burrow like 'beads on a string' (Blake 1969). Larvae of this species are typically competent to settle after reaching 17 chaetigers in length (Hopkins 1958, Blake 1969). Haigler (1969) and Simon (2015) have observed that some $P$. websteri larvae are adelphophagic and reach 17 chaetigers in length within the burrow, gaining nutrition from unfertilized 'nurse' eggs, and spend little time in the plankton before being competent to settle. However, the majority of reports suggest that larvae leave the burrow soon after hatching and spend a protracted period in the plankton, perhaps as long as $45 \mathrm{~d}$ or more (e.g. Blake 1969).

Environmental variables, such as habitat availability, spatial variation in genetic selection, and local variation in hydrodynamics, can weaken the relationship between the length planktonic larval duration and levels of genetic divergence. Even so, Selkoe \& Toonen (2011) have shown that there is a consistent pattern of increasing genetic distance with increasing geographic distance, with the shape of this relationship dependent on planktonic larval duration, which serves as a proxy for dispersal in many coastal marine invertebrates. In a recent study, Williams et al. (2016) compared the degree of population structure for 2 spionid polychaetes, Boccardia polybranchia, which is not associated with shellfish aquaculture, and P. hoplura, which is. For B. polybranchia, they found evidence for isolation by distance among mtDNA sequence clades observed on either side of Cape Point, South Africa. In contrast, they detected no population structure in $P$. hoplura sampled from many of the same locations. In a similar manner, the patterns of genetic variation we observed for $P$. websteri stand in stark contrast to those observed for $P$. cornuta, even though these 2 species have a similar life history. Although $P$. cornuta does 
not bore into shells, it is considered a significant pest in shellfish aquaculture due to its propensity to construct dense aggregations of mud tubes on the exterior surface of shellfish valves and culture equipment. Rice et al. (2008) observed that North American populations of $P$. cornuta are reproductively isolated and genetic distance estimates between some populations of this species are as high as 0.86 , an order of magnitude higher than the genetic distance estimates we obtained between $P$. websteri populations.

The comparative lack of population genetic structure for pest polychaete species on shellfish farms indicates that processes other than natural dispersal are influencing the patterns of genetic diversity. For example, Williams et al. (2016) found that $P$. hoplura associated with oysters in 'offshore' farms $(>1 \mathrm{~km}$ from shore) near ports had the highest levels of genetic diversity, ostensibly due to a combination of previous aquaculture-based introductions along gene flow from wild populations that were established via ballast water introductions. In contrast, worms at 'onshore' farms $(<0.5 \mathrm{~km}$ from shore) showed lower diversity and the presence of unique haplotypes, which Williams et al. (2016) attributed to the aquaculture-mediated introductions along with the subsequent development of large local populations supported by a preponderance of local recruitment by adelphophagic larvae. In some cases, Williams et al. (2016) noted that haplotype-sharing among 'onshore' farms was likely the result of the transfer of host shellfish between farms. Overall, Williams et al. (2016) concluded that long-term importation of shellfish, proximity of farms to ports where pests may have been introduced via ballast water discharge, along with local, regional or interregional movement of shellfish hosts has led to the patterns of genetic diversity without any appreciable population structure they observed among $P$. hoplura populations in South Africa.

We observed much lower genetic diversity at 2 of our sites, farms on the Bagaduce River, Maine and in Kanoehe Bay (Moli'i Fish Pond), Hawaii, as might be expected for 'onshore' farms, given the results from Williams et al. (2016). However, there was no 'offshore' versus 'onshore' dichotomy in our study as all the farms we sampled are nearshore sites in coastal, semi-enclosed embayments or estuaries and none were located near major shipping ports. We did not sample nearby wild populations of $P$. websteri so it is impossible to ascertain whether such populations influence the patterns of variation among the farms we sampled.
Even so, the low haplotype diversity, lack of population structure and high level of haplotype sharing among farms in different ocean basins that we observed for $P$. websteri is mostly likely due to the inadvertent movement of blister worms through purposeful or accidental movement of their shellfish hosts. Sindermann (1990) noted that the intentional transport of oysters likely exceeds that of all other marine species. A wide variety of species have managed to 'hitchhike' and have been introduced to new locations along with their shellfish hosts. For example, Cohen \& Carlton (1995) estimated that introductions of eastern and Pacific oysters have been responsible for upwards of $20 \%$ of the non-native introductions into San Francisco Bay. Blister worms have been among the 'hitchhiking' species. For example, Read (2010) used historical records to trace the arrival of $P$. websteri and the closely related $P$. haswelli into New Zealand waters from Australia in the 1970s, an event he suggests is related to the introduction of Pacific oysters.

As noted earlier, Hartman (in Loosanoff \& Engle 1943) provided the first description of $P$. websteri based on a specimen from Milford Harbor, Connecticut, USA. However, given the confusion over blister worm species identification in the literature, it is difficult to determine whether $P$. websteri is native or introduced to the US Atlantic Coast. In fact, there is the strong possibility that the introduction of Pacific oysters Crassostrea gigas from Japan to North American waters may have played a role in the introduction of $P$. websteri to North American waters. Chew (1979) describes several attempts to introduce adult Pacific oysters from Japan to Washington State in the early 1900s. Later efforts to increase oyster cultivation in Washington and California (USA), and British Columbia (Canada) relied on the importation of 'massive amounts' of Pacific oyster seed (National Research Council 2004); although shell-boring polychaetes are not commonly found in seed oysters, that seed was attached to cultch (adult shell). From the 1930s up to the 1970s, C. gigas from the Pacific coast was introduced to multiple Atlantic and Gulf Coast states, including Louisiana, Alabama, New Jersey, Connecticut, Massachusetts and Maine (National Research Council 2004), which may have brought $P$. websteri eastward.

However, the first non-native oyster introduced to the West Coast of the United States was C. virginica. As early as 1869, oystermen in northern California were importing eastern oysters by railroad for culture in San Francisco Bay (National Research Council 2004). There are well-recognized introductions of 
species that 'hitchhiked' along with the introduced C. virginica, such as the slipper shell Crepidula fornicata and oyster drill Urosalpinx cinerea. Both are found on the West Coast today (National Research Council 2004). However, there has been less opportunity for the movement of shellfish hosts westward across the Pacific. Further, our analysis of $P$. websteri mtCOI sequences indicates that the most common haplotype in the Guangdong Province, China, population, H3, is the most likely ancestral or an outgroup haplotype among the haplotypes currently available for this species. In addition, we found that sequence diversity is greatest among the Chinese sequences (Table 2), and this diversity encompasses the variation in the rest of the dataset. Based on these patterns, we suggest an Asian origin for P. websteri, although additional sampling that includes natural or wild populations of the species will strengthen such a conclusion. Even if the initial introduction or direction of spread of $P$. websteri cannot be ascertained, our results are consistent with the conclusion of Simon \& Sato-Okoshi (2015) that molluscan aquaculture is a significant vector for the movement of pest polychaete species; in this case, the repeated movement of shellfish has led to high rate of movement and genetic homogeneity among $P$. websteri populations, worldwide.

Acknowledgements. We thank Bill Walton of Auburn University, Dan Ward of Ward Aquafarms, LLC, Ted Cooney of Madhouse Oysters, Eric Moran of Bagaduce River Oyster Co., and Kimon McCarty of Kualoa Ranch, Hawaii, for generously donating oysters and their blister worm pests. Financial support provided by the Maine Agriculture and Forestry Experiment Station (ME021511) and USDA Northeast Sustainable Agriculture Research and Education Program (LNE14-336).

\section{LITERATURE CITED}

Bailey-Brock JH (2000) A new record of the polychaete Boccardia proboscidea (family Spionidae) imported to Hawaii with oysters. Pac Sci 54:27-30

Bergman KM, Elner RW, Risk MJ (1982) The influence of Polydora websteri borings on the strength of the shell of the sea scallop, Placopecten magellanicus. Can J Zool 60: 2551-2556

Blake JA (1969) Reproduction and larval development of Polydora from Northern New England (Polychaeta: Spionidae). Ophelia 7:1-63

Blake JA (1971) Revision of the genus Polydora from the East coast of North America (Polychaeta: Spionidae). Smithson Contrib Zool 75, Smithsonian Institute Press, Washington, DC

Blake JA, Evans JW (1973) Polydora and related genera as borers in mollusk shells and other calcareous substrates. Veliger 15:235-249
Bower SM (2004) Synopsis of infectious diseases and parasites of commercially exploited shellfish: shell-boring polychaetes of oysters. Fisheries and Oceans Canada. www.dfo-mpo.gc.ca/science/aah-saa/diseases-maladies/ sbpoy-eng.html

Carr CM, Hardy SM, Brown TM, Macdonald TA, Herbert PDN (2011) A tri-oceanic perspective: DNA barcoding reveals geographic structure and cryptic diversity in Canadian polychaetes. PLOS ONE 6:e22232

Chew KK (1979) The Pacific oyster (Crassostrea gigas) in the West Coast of the United States. In: Mann R (ed) Proc Symp Exotic Species in Mariculture: Case Histories of the Japanese oyster Crassostrea gigas (Thunberg), with Implications for Other Fisheries. MIT Press, Cambridge, MA, p 54-82

* Clement M, Posada D, Crandall KA (2000) TCS: a computer program to estimate gene genealogies. Mol Ecol 9: 1657-1659

Cohen AN, Carlton JT (1995) Nonindigenous aquatic species in a United States estuary: a case study of the biological invasions of the San Francisco Bay and delta: a report for the United States Fish and Wildlife Service. Washington, DC

* Dunphy BJ, Wells RMG, Jeffs AG (2005) Polydorid infestation in the flat oyster, Tiostrea chilensis: hyposaline treatment for an aquaculture candidate. Aquacult Int 13: 351-358

G Guindon S, Dufayard JF, Lefort V, Anisimove M, Hordijk W, Gascuel O (2010) New algorithms and methods to estimate maximum-likelihood phylogenies: assessing the performance of PhyML 3.0. Syst Biol 59:307-321

*Haigler SA (1969) Boring mechanism of Polydora websteri inhabiting Crassostrea virginica. Am Zool 9: 821-828

Hellberg ME, Burton RS, Neigel JE, Palumbi SR (2002) Genetic assessment of connectivity among marine populations. Bull Mar Sci 70S:273-290

Hopkins SH (1958) The planktonic larvae of Polydora websteri Hartman (Annelida, Polychaeta) and their settling on oysters. Bull Mar Sci 8:268-277

Huerta-Cepas J, Serra F, Bork P (2016) ETE 3: reconstruction, analysis and visualization of phylogenomic data. Mol Biol Evol 33:1635-1638

Lafferty KD, Kuris AM (1996) Biological control of marine pests. Ecology 77:1989-2000

Lefort V, Longueville JE, Gascuel O (2017) SMS: Smart model selection in PhyML. Mol Biol Evol 34:2422-2424

Leigh JW, Bryant D (2015) POPART: full-feature software for haplotype network construction. Methods Ecol Evol 6: 1110-1116

Kibrado P, Rozas J (2009) DNASP V5: a software for comprehensive analysis of DNA polymorphism data. Bioinformatics 25:1451-1452

Light WJ (1978) Spionidae. Polychaeta. Annelida. The Boxwood Press, Pacific Grove, CA

Loosanoff VL, Engle JB (1943) Polydora in oysters suspended in the water. Biol Bull 85:69-78

Lunz GR (1940) The annelid worm, Polydora, as an oyster pest. Science 92:310

National Research Council (2004) Nonnative oysters in the Chesapeake Bay. The National Academies Press, Washington, DC

Nell J (2007) Controlling mudworm in oysters. Primefact 590, NSW Dept of primary Industries, Nelson Bay

* Radashevsky VI, Olivares C (2005) Polydora uncinata (Poly- 
chaeta: Spionidae) in Chile. An accidental transportation across the Pacific. Biol Invasions 7:489-496

Read GB (2010) Comparison and history of Polydora websteri and P. haswelli (Polychaeta:Spionidae) as mud-blister worms in New Zealand shellfish. NZ J Mar Freshw Res 44:83-100

Rice SA, Karl S, Rice KA (2008) The Polydora cornuta complex (Annelida: Polychaeta) contains populations that are reproductively isolated and genetically distinct. Invertebr Biol 127:45-64

Sato-Okoshi W, Abe H (2013) Morphology and molecular analysis of the 18S rRNA gene of oyster shell borers, Polydora species (Polychaeta: Spionidae) from Japan and Australia. J Mar Biol Assoc UK 93:1279-1286

Sato-Okoshi W, Okoshi K, Abe H, Li JY (2013) Polydorid species (Polychaeta, Spionidae) associated with commercially important mollusk shells from eastern China. Aquaculture 406-407:153-159

Sato-Okoshi W, Abe H, Nishitani G, Simon CA (2017) And then there was one: Polydora uncinata and Polydora haplura (Annelida: Spionidae), the problematic Polydorid pest species represents a single species. J Mar Biol Assoc UK 97:1675-1684

Selkoe KS, Toonen RJ (2011) Marine connectivity: a new look at pelagic larval duration and genetic metrics of dispersal. Mar Ecol Prog Ser 436:291-305

Simon CA (2015) Observations on the composition and larval developmental modes of polydorid pests of farmed oysters (Crassostrea gigas) and abalone (Haliotis midae) in South Africa. Invertebr Reprod Dev 59:124-130

Simon CA, Sato-Okoshi W (2015) Polydorid polychaetes on

Editorial responsibility: Kevin Glover,

Bergen, Norway farmed molluscs: distribution, spread and factors contributing to their success. Aquacult Environ Interact 7 : $147-166$

Sindermann CJ (1990) Principal diseases of marine fish and shellfish, 2nd edn. Academic Press, San Diego, CA

* Tamura K, Stecher G, Peterson D, Filipski A, Kumar S (2013) MEGA6: Molecular Evolutionary Genetics Analysis Version 6.0. Mol Ecol Evol 30:2725-2729

Wargo RN, Ford SE (1993) The effect of shell infestation by Polydora sp. and infection by Haplosporidium nelsoni (MSX) on the tissue condition of oysters, Crassostrea virginica. Estuaries 16:229-234

Williams L, Matthee CA, Simon CA (2016) Dispersal and genetic structure of Boccardia polybranchia and Polydora hoplura (Annelida: Spionidae) in South Africa and their implactions for aquaculture. Aquaculture 465: 235-244

Williams LG, Karl SA, Rice S, Simon C (2017) Molecular identification of polydorid polychaetes (Annelida: Spionidae): Is there a quick way to identify pest and alien species? Afr Zool 52:105-117

* Ye L, Cao C, Tang B, Yao T, Wang R, Wang J (2017) Morphological and molecular characterization of Polydora websteri (Annelida: Spionidae) with remarks on relationship of adult worms and larvae using mitochondrial COI gene as a molecular marker. Pak J Zool 49: 699-710

Zottoli RA, Carriker MR (1974) Burrow morphology, tube formation, and microarchitecture of shell dissolution by the spionid polychaete Polydora websteri. Mar Biol 27: 307-316

Submitted: March 7, 2018; Accepted: August 9, 2018 Proofs received from author(s): September 25, 2018 